\title{
Lip Cancer: Epidemiologic, Clinical, Evolutive, and Therapeutical Aspects
}

\author{
Rafik $\mathrm{A}^{* 1}$, Taquafi $\mathrm{S}^{1}$, Chabbak $\mathrm{H}^{1}$, Jouhri $\mathrm{K}^{1}$, Diouri $\mathrm{M}^{2}$, Bahechar $\mathrm{N}^{2}$ and Chlihi $\mathrm{A}^{2,3}$ \\ ${ }^{1}$ Resident doctor (M.D), National Center of burns and plastic surgery, Casablanca Morocco \\ ${ }^{2}$ Professor of higher education (PHD) in plastic surgery \\ ${ }^{3}$ Chief of the National Center of burns and plastic surgery, Casablanca Morocco \\ *Corresponding author: Rafik A, Resident doctor (M.D), National Center of burns and plastic surgery, \\ Casablanca Morocco, E-mail: aminerafik8@gmail.com \\ Citation: Rafik A, Taquafi S, Chabbak H, Jouhri K, Diouri M, et al. (2015) Lip Cancer: Epidemiologic, Clinical, \\ Evolutive, and Therapeutical Aspects. J Cancer Sci Clin Oncol 2(2): 204. doi: 10.15744/2394-6520.2.301
}

Received Date: March 29, 2015 Accepted Date: September 08, 2015 Published Date: September 10, 2015

\begin{abstract}
Introduction: Lip cancer is relatively common, despite the progress seen recently in Morocco in terms of labial-jugal cancer reconstructions. Lip cancer is often seen in advanced stages and poses management problems.

Materials and Methods: We present a series of 130 cases of lip cancer collected at the National Centre of Plastic Surgery and Burns Unit at the University Hospital of Casablanca over a period of 5 years, from January 2010 to December 2014. The objective is to analyse epidemiological data, treatment and results.

Results: The average age of patients was 68 years, with a sex ratio of 3. Squamous cell carcinoma were predominant. The tumoral lesions sat preferentially at the lower lip in $57.8 \%$ of the cases. $43.8 \%$ of patients were classified TI-T2, and $52.4 \%$ were classified as T3-T4. Tumor resection was complete in 125 cases and repair was immediate in all cases except one. Neck dissection was required in $33 \%$ of cases. Adjuvant therapy primarily consisted of external beam radiation on lymph nodes. The most used means of reconstruction in our series after direct sutures is Karapandzic flap in $46 \%$ of the cases. The rate of local recurrence is estimated $6.4 \%$, and the 3 -year survival is $95 \%$. The aesthetic and functional results are considered satisfactory in $92 \%$ of the cases subject to operation.
\end{abstract}

Conclusion: Lip cancer must be diagnosed at an early stage; precancerous stages are keys to detect and treat the two main concerns during intervention, namely the carcinological aspect and functional and aesthetic aspect.

Keywords: Lip Cancer; Lip Reconstruction; Risk Factor; Carcinoma

\section{Introduction}

Lips cancer is a frequent pathology, representing 1/5 of upper aerodigestive tract cancers and 15-30\% of all encephalic extremity cancers [1]. In the US, 3500-4000 new lips cancer cases are diagnosed every year, being a 2 per 100000 incidence and 500000 new cases worldwide [2]. Oncologic staging for lip cancers follows the common accepted regimen from the American Joint Committee on Cancer (AJCC) and is grouped with oral cancers. Lip cancer is frequently grouped analytically with oral cavity cancers; however, the etiopathogenesis is notably different. The majority of lip cancers are preceded by a preexisting lesion, and the lower lip is the index tumor location in nearly $92 \%$ of lip cancers. In our context, this cancer is noticed at very advanced stages, thus causing a problem of medical care.

The aim of this study was to retrospectively analyze clinical features, treatment modalities, and postoperative follow-up findings of patients diagnosed with a cancer of the lip at the Clinic for the plastic Surgery at the national center of burns and plastic surgery, Casablanca, Morocco.

\section{Materials and Methods}

This is a retrospective study of 130 cases of lips cancer, collated in the Casablanca Ibn Rochd university hospital Burns and Plastic Surgery National Center from January 2010 to December 2014. All available information was collected regarding: age, sex, profession and medical and surgical history were noted for each patient. A complete, general inspection was carried out for all of our patients. In order to determine the local, regional and remote tumor extension, a complementary paraclinical balance sheet was realized according to clinical orientations. The results, according to the technique being used, seat and expansion of the defect were assessed with objective, functional and aesthetic criteria. The following criteria were taken into account when evaluating the post-operative results:

- Excellent aesthetic results: invisible scar and normal aspect of the lip.

- Acceptable aesthetic results: closely $(20 \mathrm{~cm})$ visible scar, the anatomical aspect of a less well-defined structure.

- Medial aesthetic results: when morphology changes without important functional trouble.

- Poor aesthetic results: modified anatomy. 


\section{Results}

\section{Epidemiological data}

The age of our patients varies between 35 years and 80 years, with an average age of 68 years. A male predominance was noted: There were $100(76.9 \%)$ males and 30 (23.1\%) females. In this series, the majority of our patients were exposed for a long period to the sunlight, and we faced difficulty mentioning the presence or absence of precancerous lesions that might engender lips carcinoma. The independent factors of risk were represented by the solar exposure and nicotinic consumption. Table 1 shows the set of risks factors.

\begin{tabular}{|c|c|c|}
\hline & Number (n) & Rate (\%) \\
\hline Smokers & 65 & $50 \%$ \\
\hline Alcohol & 24 & $18.4 \%$ \\
\hline Oral and dental health & 70 & $53.8 \%$ \\
\hline Precancerous lesions & 18 & $13.8 \%$ \\
\hline
\end{tabular}

\section{Clinical data}

Table 1: The risk factors in our population $(\mathrm{n}=130)$

The mean interval between the onset of the lesion and the first consultation is 12 months. Hundred patients consulted late, after one year. The lower lip involvement was predominant in our series (Figure 1). Microscopic study of the tumor biopsy sample reports quite clear predominance of squamous cell carcinoma, met in 101 cases, being $77.7 \%$ against 28 cases of only basal cell carcinoma (21.6\%). Only one patient was diagnosed for melanoma. The ulcerative burgeoning macroscopic aspect was by far the predominant and was found in 53 patients against 30 cases of ulcer aspect. The burgeoning aspect was only found in 18 patients. However, it was noted that patients with lymphadenopathy was holders of isolated carcinoma of the lower lip or commissure involvement ( 5 cases). Main tumor characteristics are summarized in Table 2.

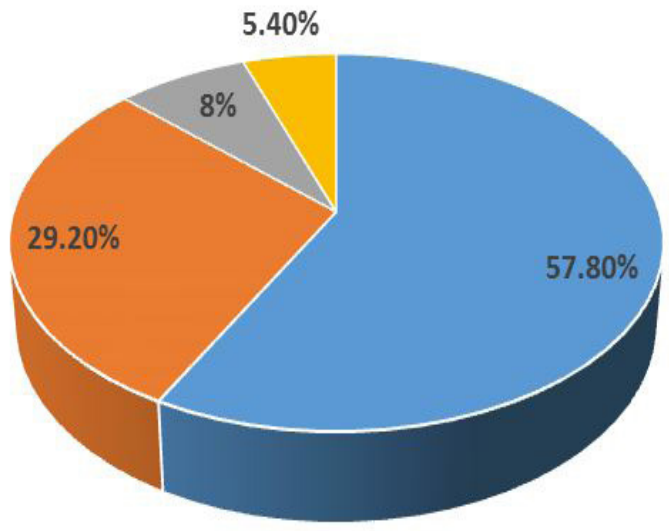

- lower lip

" commissure

In upper lip

" upper and lower lip

Figure 1: Rate of Tumor location at the lips $(\mathrm{n}=130)$

\begin{tabular}{|c|c|c|}
\hline & Number (n) & Rate (\%) \\
\hline Tumor size & & \\
\hline T1 & 33 & $25.3 \%$ \\
\hline T2 & 29 & $22.3 \%$ \\
\hline T3 & 43 & $33.2 \%$ \\
\hline T4 & 25 & $19.2 \%$ \\
\hline Histopathological exam & & \\
\hline Bquamous cell carcinomas(SCC) & 101 & $77.7 \%$ \\
\hline Melanoma & 28 & $21.6 \%$ \\
\hline Nodal involvement & 1 & $0.7 \%$ \\
\hline N1 & 17 & \\
\hline N2 & 26 & $20 \%$ \\
\hline
\end{tabular}

Table 2: Tumor characteristics in our series $(n=130)$ 
Fourty three of our patients had clinically palpable cervical lymphadenopathy with a variable seat (submandibular region +++ ). The extension balance sheet was performed for all patients in our series, without showing distant metastases images.

\section{Therapeutic data}

Surgical treatment: Tumor resection was the rule among the majority of our patients (128 cases), following a safety margin adapted to the suspected or confirmed histologic type and tumor size. Thus, a margin of $1 \mathrm{~cm}$ was required for squamous cell carcinoma, melanoma, and 3 to $5 \mathrm{~mm}$ for oncologic resection of basal cell carcinomas. Moreover, the margin of resection was complete in 125 patients and incomplete in 3 others referred for radiotherapy. Lymph node dissection was performed in 43 patients with cervical lymphadenopathy. The final histological examination showed lymph node tumor involvement with capsular effraction in three patients.

The reconstruction was often immediate after tumor resection. Direct suture was performed in 57 patients: 33 classified T1 and the other 29 classified T2. The use of locoregional flaps was in 59 patients (Figure 2). For the remote flaps, in our series, superficial temporal pedicle scalp flap was performed in 3 cases, and the pectoralis major flap has been used 4 times.

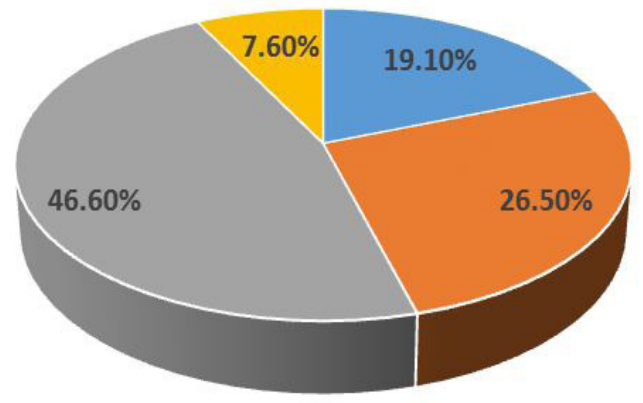

- Estlander flap

- Gillies fan flap

- Karapandzic Flap

- Webster-Bernard Flap

Figure 2: Different techniques of the reconstruction by loco regional flaps

Radiotherapy and Chemotherapy: Three patients were referred for postoperative radiotherapy, while 2 other patients, given their general condition and associated defects including one with involvement of both lips, underwent palliative radiotherapy.

The patient with nodular melanoma, seating at the level of the lower lip with submandibular ipsilateral lymph nodes, has been the only case who benefited from surgery and chemotherapy association.

\section{Evolutionary data}

Fifteen patients had local infection with dropping suture under control by medical treatment, and 2 patients had partial necrosis of the pectoral flap. The oncological results were essentially based on the rate of recurrence, the appearance of new lesions and the presence of metastases. Within the limits of our 36 months follow-up, and irrespective of the patients in whom resection was incomplete, eight patients had tumor recurrence.

The aesthetic results for our 128 operated patients were deemed excellent in $70 \%$ of cases and good in $22.5 \%$ of cases. Microstomia was observed in five of our patients, hence the indication of commissuroplasty in a second time. Functionally, salivary incontinence was noted in seven patients.

\section{Discussion}

Squamous carcinomas of the lip (SCC) represent 10 to $20 \%$ of tumors of the oral cavity [3]. The exact incidence of carcinoma of the lip is difficult to assess because they are subject to a comprehensive epidemiological approach with cancers of the upper aerodigestive tract and cancer of the esophagus. The frequency of cancer of the lips in relation to oral cancer is 6 to 20\% for GUELBERD [4], and only $2 \%$ in the series of Lotfi Ben Slama at the Salpêtrière Hospital [5]. In Morocco, we have no epidemiological studies indicating the impact of labial carcinoma.

Lip cancers mostly affect the male-sex subjects whose age range is 60-70 years. Thus our series joins all summarized series [6-8] in Table 3, with a peak frequency in the range of 70 to 80 years and a sex ratio of 3 . The etiological factors of these tumors are represented mainly by sun exposure, which is considered the major risk factor: in our series, $70 \%$ of our patients either are from rural areas or work outdoors without protection. This agrees well with the literature data. [9]. Chronic bad oral hygiene, tobaccoalcohol intoxication [10-12] are factors often cited in the literature but no study has so far been able to confirm it as an etiological factor; other factors have been found in our series consistent with the literature, such as: precancerous lesions observed in 4 of our patients (actinic keratosis and melanoderma lesions). 


\begin{tabular}{|c|c|c|c|c|}
\hline & $\begin{array}{l}\text { S.AYACHI [6] } \\
{[2005]}\end{array}$ & $\begin{array}{l}\text { E.DEDIOL [7] } \\
{[2008]}\end{array}$ & $\begin{array}{l}\text { M.VUKADINOVIC [8] } \\
\text { [2007] }\end{array}$ & $\begin{array}{l}\text { Our study } \\
{[2014]}\end{array}$ \\
\hline Age (mean) & 47years & 67 years & 64years & 68years \\
\hline Sex ratio & 3 & 4 & 5 & 3 \\
\hline Localisation & $\begin{array}{l}\text { Lowerlip } \\
68 \%-78 \%\end{array}$ & $\begin{array}{c}\text { Lowerlip } \\
95 \%\end{array}$ & $\begin{array}{l}\text { Lowerlip } \\
92 \%\end{array}$ & $\begin{array}{c}\text { Lowerlip } \\
57.8 \%\end{array}$ \\
\hline Histologic analysis & $\begin{array}{l}\text { SCC } \\
81 \%\end{array}$ & $\begin{array}{l}\text { SCC } \\
95 \%\end{array}$ & $\begin{array}{l}\text { SCC } \\
90 \%\end{array}$ & $\begin{array}{c}\text { SCC } \\
77.7 \%\end{array}$ \\
\hline $\begin{array}{c}\text { Classification } \\
\text { TxNxM0 }\end{array}$ & $\begin{array}{c}\mathrm{T} 1-\mathrm{T} 269 \% \\
\mathrm{~N}+10.4 \%\end{array}$ & $\begin{array}{c}\text { T1-T2 } 86 \% \\
\mathrm{~N}+5 \%\end{array}$ & $\begin{array}{c}\mathrm{T} 1-\mathrm{T} 290 \% \\
\mathrm{~N}+26.5 \%\end{array}$ & $\begin{array}{c}\text { T1-T2 } 43.8 \% \\
\mathrm{~N}+33 \%\end{array}$ \\
\hline Reconstruction flaps & $\begin{array}{c}\text { Etslander } \\
43.7 \%\end{array}$ & $\begin{array}{c}\text { Webster-Bernard } \\
10.2 \%\end{array}$ & $\begin{array}{c}\text { Karapandzic } \\
22.5 \%\end{array}$ & $\begin{array}{c}\text { Karapandzic } \\
46.6 \%\end{array}$ \\
\hline $\begin{array}{l}\text { Recurrence } \\
\text { rate }\end{array}$ & - & $4.6 \%$ & $10.8 \%$ & $6.4 \%$ \\
\hline
\end{tabular}

Table 3: Comparison of the literature series

Our series is consistent with the literature and majority of authors as to the great predilection of squamous cell carcinoma in the lower lip [13]. However, high commissural effect has been reported in our statistics; in fact, these are lower lip effects extending to the commissure. The majority of our patients consulted at a late stage: consultation of $74 \%$ of patients exceeded 12 months. Lymph node involvement is often late; the lymphophilie is submental, submaxillary and subdigastric. The frequency of primary lymphatic metastasis varies from 2 to $7 \%$ during the first consultation [14,15]. The presence of lymph nodes was noted in 43 of our patients, being $33 \%$, all with carcinoma of the lower lip; this incidence is relatively important with regard to the literature; this is explained by the delays of medical care and locally advanced forms.

No distant metastases were noted in our series: sought by the general examination and confirmed by radiology. A retrospective study of 186 patients with carcinoma of the lips revealed 4 cases of distant metastases, being $2.16 \%$ at bone level with a concomitant axillary node invasion. These tumors are classified T2-T4 [16].

The treatment of choice is surgery because it allows a histological control of the excision specimen and allows asserting, or not, its completeness. The surgical margins vary according to histological type [17]. Thus, surgery was used first in most of the series [6-8].

Palpation and imaging data guide the indication of a lymph node dissection, which in practice is not systematic. Calfino. L [18] practice systematic lymphadenectomy for all squamous cell carcinomas of the lips; they found only three histological lymph node invasions on 80 N0 patients; they recommend a simple,sub-mento-sub-mandibular sub-digastric bilateral above-omo-hyoid, node monitoring for N0. In our study, in presence of palpable lymph nodes, the lymphadenectomy with frozen section guide the surgical approach imposing dissection in case of lymph node involvement $(\mathrm{N}+)[19,20]$.

The cheiloplasty varies according to the authors, tumor characteristics and the importance of lip infection. We notice that the hetero-labial flaps were used after direct suture and gave satisfaction every time the defect did not exceed the lip region. According to JP Pepper and SR Baker [21], repair techniques by direct suture, Abbe flap and those using the Karapandzic technique have good results, functionally and aesthetically. Stairs repair techniques, Webster, Etslanderand Gilles' fan flap ensure a satisfactory functional outcome, but, aesthetically, there is significant scarring. Although remote shreds make it possible to ensure the complete repair of the defect, they are insufficient functionally and aesthetically [22]. In our series: the aesthetic result was considered excellent in reconstructions using direct suture, hetero-labial tatters and Karapandzicshreds (Figure 3), being 70\% of cases. It was deemed acceptable, for $22.5 \%$, in the reconstructions by nasolabial flaps and Camille Bernard's flap; while it was considered bad in $8.5 \%$ of cases for the reconstruction by the flap of the major pectoralis and Dufourmentel scalp flap. The functional result was good for $92 \%$ of cases.

In a series of 232 cases of $\mathrm{K}$ McCombe [23], the local recurrence occurred in $7.6 \%$ of patients, while regional metastases developed in $4.3 \%$ of patients when the treatment undertaken was surgery. The survival rate at 5 years is above $85 \%$ for the majority of the authors and can reach $98 \%[13,24]$. In our series, the recurrence rate is estimated at $6.4 \%$, but the survival rate at 5 years is difficult to assess, as the majority of patients do not return regularly for monitoring consultations, especially after 3 years.

\section{Conclusion}

Lip cancer remains a significant health problem. Currently, it seems that the epidemio-clinical profile observed in our series is characterized by the frequency of locally advanced forms to that reported in the literature. The treatment is mainly based on surgery abiding by oncological rules and the reconstruction of the defect with different lip reconstruction; these allow us to reach a more or less satisfactory result, which nonetheless remains a challenge and sometimes disappointing in locally advanced cases. Primary prevention remains the undisputed way to fight these tumors by raising awareness of the public against the harmful effects of sun exposure and strict monitoring of precancerous lesions. 


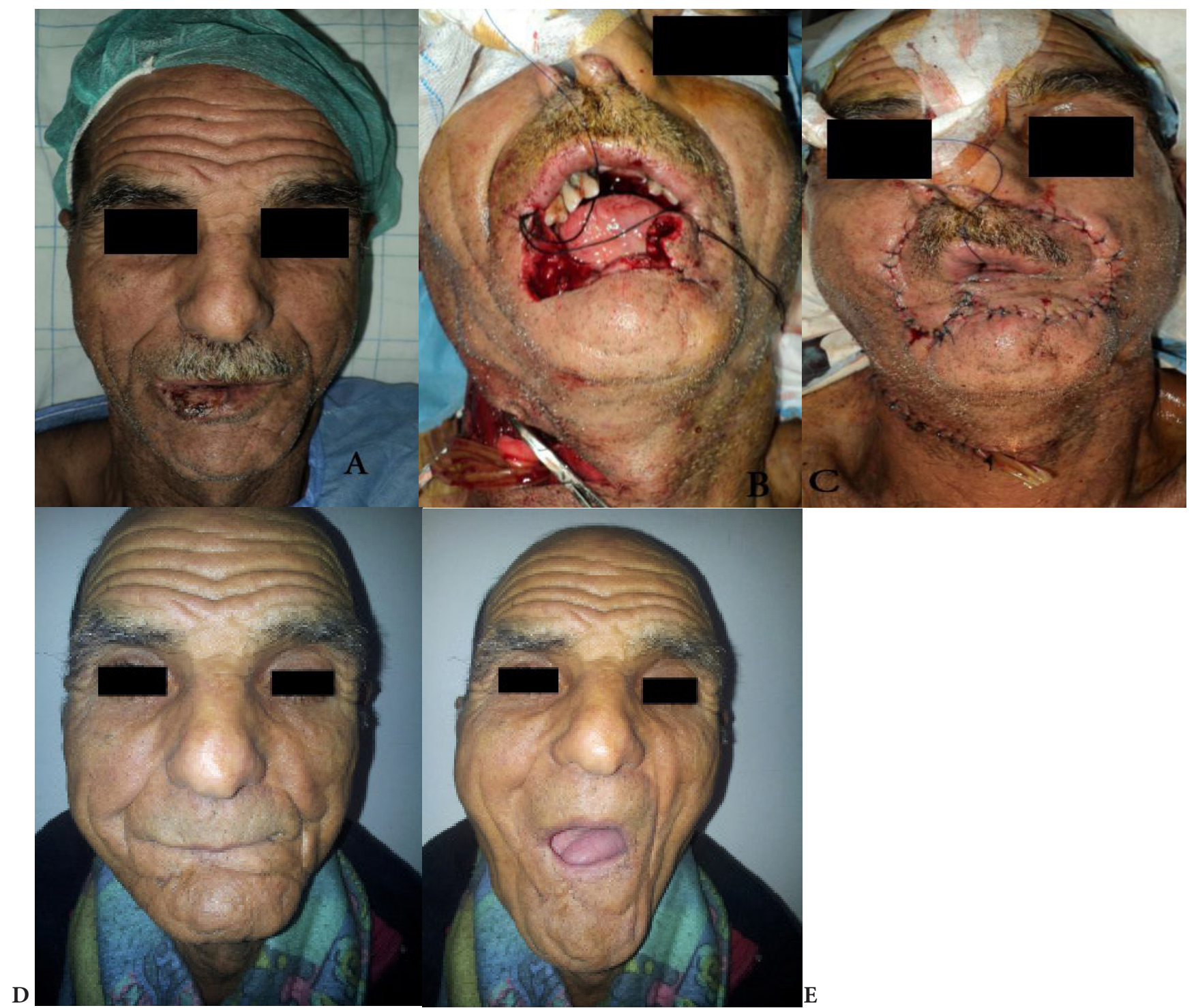

Figure 3: A: Patient aged 54 has a squamous cell carcinoma infiltrating ulcerated. B: Tumoral excision associated with neck dissection. C: Reconstruction with Karapandzic flap. D and E: Results after 18 months

\section{References}

1. Perie S, Meyers M, Mazzaschi O, De Crouy Chanel O, Baujat B, et al. (2014) Epidemiology and anatomy of head and neck cancers. Bull Cancer 101: 404-10. 2. Smith RA, Cokkinides V, Brawley OW (2009) Cancer screening in the United States, 2009: a review of current American Cancer Society guidelines and issues in cancer screening. CA Cancer J Clin 59: 27-41.

3. Lee CH, Lee KW, Fang FM, Wu DC, Tsai SM, et al. (2012) The neoplastic impact of tobacco-free betel-quid on the histological type and the anatomical site of aerodigestive tract cancers. Int J Cancer 131: E733-43.

4. Chomette G, Auriol M, Raphael M, Guilbert F, Vaillant JM (1990) Extra-nodal lymphoma of the cervicofacial region: anatomo-pathological aspects. Rev Stomatol Chir Maxillofac 1: 22-6.

5. Slama LB (2001) Precancerous lesions of the buccal mucosa. Rev Stomatol Chir Maxillofac 102 : 77-108.

6. Ayachi S, Chelbi M, Moetamri R, Khochtali H, Bakir A (2005) O 5-6 Repair Loss of Substances Surgical transfixing Lips. Rev Stomatol Chir Maxillofac 106: $17-8$.

7. Dediol E, Lukšić I, Virag M (2008) Treatment of squamous cell carcinoma of the lip. Coll Antropol 32: 199-202.

8. Vukadinovic M, Jezdic Z, Petrovic M, Medenica LM, Lens M (2007) Surgical management of squamous cell carcinoma of the lip: analysis of a 10-year experience in 223 patients. J Oral Maxillofac Surg 65: 675-9.

9. Pătraşcu V, Ciurea R (2013) Lip Squamous Carcinoma-Epidemiologic, Clinical, Evolutive and Therapeutical Aspects. Curr Health Sci J 39 : $84-92$.

10. Czerninski R, Zini A, Sgan-Cohen HD (2010) Lip cancer: incidence, trends, histology and survival: 1970-2006. Br J Dermatol 162: 1103-9.

11. Leiter U, Garbe C (2008) Epidemiology of melanoma and nonmelanoma skin cancer--the role of sunlight. Adv Exp Med Biol 624: 89-103.

12. Xiang F, Lucas R, Hales S, Neale R (2014) Incidence of nonmelanoma skin cancer in relation to ambient UV radiation in white populations, 1978-2012: empirical relationships. JAMA Dermatol 150: 1063-71. 
13. McClure S, Jakubowski J (2014) Complications Associated with Treatment of Lip Cancer. Lip Cancer 127-35.

14. Gonzalez-Garcia R, Naval-Gias L, Rodriguez-Campo FJ, Sastre-Perez J, Munoz-Guerra MF, et al. Contralateral lymph neck node metastasis of squamous cell carcinoma of the oral cavity: a retrospective analytic study in 315 patients. J Oral Maxillofac Surg 66: 1390-8.

15. Gonzalez-Garcia R, Naval-Gias L, Roman-Romero L, Sastre-Perez J, Rodriguez-Campo FJ (2009) Local recurrences and second primary tumors from squamous cell carcinoma of the oral cavity: a retrospective analytic study of 500 patients. Head Neck 31: 1168-80.

16. Vahtsevanos K, Ntomouchtsis A, Andreadis C, Patrikidou A, Karakinaris G, et al. (2007) Distant bone metastases from carcinoma of the lip: a report of four cases. Int J Oral Maxillofac Surg 36: 180-5.

17. Staub G, Revol M, May P, Bayol JC, Verola O, et al. (2008) Excision skin margin and recurrence rate of skin cancer: a prospective study of 844 cases. Ann Chir Plast Esthet 53: 389-98.

18. Califano L, Zupi A, Massari PS, Giardino C (1994) Lymph-node metastasis in squamous cell carcinoma of the lip: a retrospective analysis of 105 cases. Int J Oral Maxillofac Surg 23: 351-5.

19. Jol JA, van Velthuysen ML, Hilgers FJ, Keus RB, Neering H, et al. (2003) Treatment results of regional metastasis from cutaneous head and neck squamous cell carcinoma. Eur J Surg Oncol 29: 81-6.

20. Puri SK, Fan CY, Hanna E (2003) Significance of extracapsular lymph node metastases in patients with head and neck squamous cell carcinoma. Curr Opin Otolaryngol Head Neck Surg 11: 119-23.

21. Pepper JP, Baker SR (2013) Local flaps: cheek and lip reconstruction. JAMA Facial Plast Surg 15: 374-82.

22. Langstein HN, Robb GL (2005) Lip and perioral reconstruction. Clin Plast Surg 32: 431-45.

23. McCombe D, MacGill K, Ainslie J, Beresford J, Matthews J (2000) Squamous cell carcinoma of the lip: a retrospective review of the Peter MacCallum Cancer Institute experience 1979-88. Aust N Z Surgery 70: 358-61.

24. Ozturk K, Gode S, Erdogan U, Akyildiz S, Apaydin F (2014) Squamous cell carcinoma of the lip: survival analysis with long-term follow-up. Eur Arch Otorhinolaryngol. 